\section{Reproductive analyses of intraspecific Paspalum notatum Flügge hybrids}

\author{
Karine Cristina Krycki ${ }^{1}$, Marília Tedesco ${ }^{1}$, Vitória Rodrigues ${ }^{1}$, \\ Roberto Luis Weiler ${ }^{1}$, André Pich Brunes ${ }^{1}$, Miguel Dall'Agnol ${ }^{1}$ \\ and Carine Simioni ${ }^{{ }^{*}}$
}

\begin{abstract}
Paspalum notatum is an important forage native to Southern Brazil and one of the most promising fodder species in terms of productivity, quality, resistance and growth speed. The objective of this study was to evaluate the reproductive mode and fertility of hybrid progenies resulting from artificial crosses among artificially duplicated sexual plants, selected intraspecific hybrids of the UFRGS breeding program and apomictic ecotypes of the species. The resulting $F_{1}$ progenies were represented by 24 plants with high pollen viability (varying from 82.15 to $99.67 \%$ ) and 1.2:1 segregation for the sexual: apomictic reproduction mode, indicating predominantly sexual hybrids, due to distorted segregation. In the apomictic plants, most chromosomes paired as bivalents in diakinesis. Since the low presence of abnormalities observed in the meiotic chromosome pairing and the high pollen viability of the hybrids, all plants were confirmed as promising parents for future crosses.
\end{abstract}

Keywords: Reproduction mode, meiotic behavior, pollen viability.

\section{INTRODUCTION}

Papsalum notatum, a perennial summer forage grass, is the main herbaceous product of most native pastures of Rio Grande do Sul State. The species has two forms of dispersion, via above-ground rhizomes or seeds, making it resistant to animal trampling and competitively advantageous even at locations with degraded soil and pasture (Nabinger and Dall'Agnol 2008). The native germplasm is tetraploid and displays apomictic reproduction (Forbes and Burton 1961). By the apomictic reproduction mode, the seeds are clones of the mother plant (Ortiz et al. 2013), which can be either a drawback or a valuable tool for crop improvement (Kumar et al. 2017). Historically, the breeding of apomictic plants was limited by selection, evaluation and natural perception of the occurrence of the most vigorous and highest-yielding apomictic ecotypes (Miles 2007). Many of the currently planted cultivars originate from this form of breeding (Hojsgaard et al. 2016). However, it depends on research and natural selection of superior ecotypes, which greatly limits their potential. This alternative is less viable, because unchanged natural germplasm does not provide ideal cultivars even in forage plants (Miles 2007); the pastures without variability are advantageous for animal management but represent a serious risk when planted over wide expanses of land (Simioni and Valle 2009). Since sexual diploids are frequently found in the genus Paspalum (Martínez et al. 2007), it is possible to improve apomictic species by making crosses with relatives of sexual reproduction,
Crop Breeding and Applied Biotechnology 20(1): e291620114, 2020 Brazilian Society of Plant Breeding. Printed in Brazil http://dx.doi.org/10.1590/198470332020v20n1a14

\footnotetext{
*Corresponding author: E-mail: carine.simioni@ufrgs.br (iD) ORCID: 0000-0002-0642-6980

Received: 05 September 2019 Accepted: 20 January 2020 Published: 28 February 2020
}

${ }^{1}$ Universidade Federal do Rio Grande do Sul, Departamento de Plantas Forrageiras e Agrometeorologia, Avenida Bento Gonçalves, 7712, 91.501-970, Porto Alegre, RS, Brazil 
exploiting the existing variability in polyploid types (Quarin et al. 2001). The commercial cultivar "Pensacola" of $P$. notatum (Forbes and Burton 1961) and four accessions originate from Argentina and Uruguay (Fachinetto et al. 2018) are diploids and can be used as a source of sexuality in breeding.

For the crossbreeding, the sexual genotypes must share the same ploidy level as wild autotetraploids, requiring previous chromosomal duplication of the maternal parents (Quarin et al. 2001, Miles 2007). Completely sexual tetraploid plants were obtained directly from sexual diploids by colchicine treatment (Quarin et al. 2001, Weiler et al. 2015). With the induced polyploids and the native apomictic ecotypes from Rio Grande do Sul State, Weiler et al. (2018) carried out intraspecific crosses. Progenies of 198 hybrid plants were established for agronomic assessment and the 28 most productive plants in terms of herbage accumulation and production of leaves were selected. Cytoembryological analyses and molecular markers were used to assess the reproduction mode of the hybrids, indicating segregation for apomictic and sexual genotypes (Weiler et al. 2017), also reported by Kumar et al. (2010b) and Kumar et al. (2017) in Cenchrus ciliaris, which reinforces the possibility of producing apomictic cultivars with desirable traits and using sexual genotypes as mother plants in future crosses. Barbosa et al. (2019) established them in lines and evaluated in two physiographic regions of Rio Grande do Sul (Central Depression and Campain), showing the productive potential of some of these genotypes. The selected hybrids, the native ecotypes and the duplicated plants were then used as parents in new crossing cycles, generating hybrid progenies whose reproductive evaluations are presented here.

Evaluation of fertility and analyses of the reproductive mode of the generated hybrids are necessary in breeding program, defining their usefulness and enabling intraspecific hybridizations (Krycki et al. 2016).

The objective of this study was to determine the reproduction mode and pollen viability of segregating hybrid progenies of $P$. notatum and to analyze the meiotic chromosome pairing of the plants with apomictic reproduction mode to confirm its reproductive stability, in order to be used as future parents in breeding programs. Hybrid plants with reproductive stability and high forage yield in field trials will be candidates for registration as new cultivars.

\section{MATERIAL AND METHODS}

The hybrids analyzed in this study belong to the families 'KC' ('WKS63' x 'Bagual'), 'KD' ('WKS92' x 'Bagual'), 'KE' ('D25' x 'Bagual'), 'KF' ('D16' x 'D3') and 'KN' ('B2' $x$ 'C2'). The genotypes 'WKS63' and 'WKS92' are polyploids artificially generated by Weiler et al. (2015); 'Bagual' is a native ecotype of the species; and those tagged 'B2', 'C2', 'D3' and 'D25' are intraspecific hybrids selected for their high yield potential in field evaluations (Weiler et al. 2018, Barbosa et al. 2019). The first group of parents mentioned are sexual and the second apomictic. Of the 139 resulting seeds, 24 adult plants (named KC1, KD1, KD2, KD5, KD6, KD7, KD9, KE1, KF1, KF2, KF3, KF4, KF6, KF7, KF8, KF9, KF10, KF15, KF16, KF17, KN2, KN3, KN4 and KN5) were evaluated (Table 1).

\section{Evaluation of the reproduction mode}

The progenies reproduction mode was analyzed in inflorescences collected at anthesis and were fixed in FAA [ $40 \mathrm{ml}$ 95\% ethanol: $14 \mathrm{ml}$ distilled water: $3 \mathrm{ml} 40 \%$ formalin: $3 \mathrm{ml}$ glacial acetic acid] and refrigerated in $70 \%$ alcohol until ovary dissection, alcohol dehydration and methyl salicylate clearing (Young et al. 1979, Acuña et al. 2007). About 40 ovaries per plant were examined under

Table 1. Mode of reproduction of $F_{1}$ hybrid plants

\begin{tabular}{|c|c|c|c|c|c|c|}
\hline Genotype & $\mathrm{S}^{\mathrm{a}}$ & $A^{a}$ & $\mathbf{S A}^{\mathrm{a}}$ & $\mathrm{Ul}^{\mathrm{a}}$ & $\mathbf{T}^{\mathrm{b}}$ & Mode of reproduction \\
\hline KC1 & 35 & 0 & 0 & 5 & 40 & $\operatorname{sex}^{*}$ \\
\hline KD1 & 16 & 3 & 0 & 21 & 40 & fac apo** \\
\hline KD2 & 14 & 3 & 0 & 23 & 40 & fac apo \\
\hline KD5 & 60 & 3 & 0 & 17 & 80 & fac apo \\
\hline KD6 & 28 & 0 & 0 & 32 & 60 & sex \\
\hline KD7 & 60 & 2 & 0 & 18 & 80 & fac apo \\
\hline KD9 & 23 & 0 & 0 & 17 & 40 & sex \\
\hline KE1 & 30 & 0 & 0 & 44 & 74 & sex \\
\hline KF1 & 18 & 0 & 0 & 22 & 40 & sex \\
\hline KF2 & 35 & 0 & 0 & 45 & 80 & sex \\
\hline KF3 & 7 & 6 & 0 & 67 & 80 & fac apo \\
\hline KF4 & 21 & 0 & 0 & 18 & 39 & sex \\
\hline KF6 & 13 & 1 & 0 & 66 & 80 & fac apo \\
\hline KF7 & 30 & 0 & 0 & 10 & 40 & sex \\
\hline KF8 & 0 & 31 & 10 & 8 & 49 & fac apo \\
\hline KF9 & 32 & 0 & 0 & 41 & 73 & sex \\
\hline KF10 & 14 & 3 & 0 & 23 & 40 & fac apo \\
\hline KF15 & 28 & 0 & 0 & 22 & 50 & sex \\
\hline KF16 & 12 & 5 & 0 & 58 & 75 & fac apo \\
\hline KF17 & 37 & 0 & 0 & 45 & 82 & sex \\
\hline KN2 & 26 & 0 & 0 & 54 & 80 & sex \\
\hline KN3 & 26 & 2 & 0 & 12 & 40 & fac apo \\
\hline KN4 & 19 & 0 & 0 & 61 & 80 & sex \\
\hline KN5 & 23 & 6 & 0 & 51 & 80 & fac apo \\
\hline
\end{tabular}

"sex=sexual; ${ }^{* *}$ fac apo = facultative apomictic; ${ }^{a}$ types of embryo sacs: meiotic (S); apomictic (A); sexual and apomictic in the same ovary (SA), unidentified (UI); ' total number of ovaries analyzed $(T)$. 
differential interference contrast microscopy. To determine the reproduction mode, the ovules were separated in sexual or apomictic, according to the embryo sac morphology.

\section{Meiotic chromosome pairing and pollen viability analysis}

The meiosis of pollen mother cells (PMCs) of apomictic plants derived from intraspecific crosses was analyzed.

Young inflorescences were collected and fixed in a 3:1 solution (absolute ethyl alcohol: glacial acetic acid) for $24 \mathrm{~h}$ at room temperature and then transferred to $70 \%(\mathrm{v} / \mathrm{v})$ aqueous alcohol and stored in a freezer until slide preparation. The microsporocytes (PMCs) were prepared from the inflorescences by squashing and staining with $1 \%$ propionic carmine and examinated under an optical microscope (40x). Chromosome pairing was monitored by counts at meiosis phase I, in diakinesis, in at least 20 cells per plant (Dahmer et al. 2008, Simioni and Valle 2011).

The pollen viability of both sexual and apomictic progenies plants was assessed. To this end, mature inflorescences were collected, fixed and prepared based on the same protocol as for meiotic analyses. Mature pollen was analyzed, of which the stained grains were considered viable and wrinkled or colorless grains unviable (Singh 1993). About 1000 mature pollen grains per plant were counted in four flowers per plant ( 250 pollen grains per plant), following the protocol established and used (Dahmer et al. 2008, Guerra et al. 2013, Krycki et al. 2016). The pollen viability estimate was calculated by the percentage of viable grains: number of grains considered viable divided by the total number of grains multiplied by 100 (Tedesco et al. 2019).

\section{RESULTS AND DISCUSSION}

\section{Evaluations of the reproduction mode}

The reproduction mode of all 24 plants was determined (Table 1). In the sexual plants (Figure 1a) all the ovules observed have only one embryo sac per ovule, resulting from the functional reduction of the megaspore, containing one egg cell and two polar nuclei near the micropyle and an antipodal cell cluster approaching the chalaza as previously reported (Quarin et al. 2001, Kumar et al. 2010a). Plants with two or three multiple embryo sacs, a binucleate central cell (the polar nucleus) and without antipodes were classified as apomictic (Figure 1b).

Among the analyzed hybrids, 13 sexual and 11 apomictic genotypes were found. The sexual to apomictic ratio of the genotypes was 1.2:1, close to the expected 1:1 for tetrasomic monogenic inheritance with dominant apospory. In other evaluations of the reproductive mode of segregating $P$. notatum hybrid progenies, were found sex:apo ratios of 2.8:1 (Martínez et al. 2001); 6.5:1 (Stein et al. 2004); 4.6:1 and 4.3:1 in the first and second generations, respectively (Acuña et al. 2011) and 1:2.1 (Weiler et al. 2017). Some results showed a distortion, trending to a deviation towards sexual reproduction. According to Martínez et al. (2001), the apo-locus in $P$. notatum is linked to a lethal allele responsible for distorted segregation rates. Burton (1982) showed that the environment has little or no effect on the apomictic expression in P. notatum. Zilli et al. (2015) reported segregation rates between sexual and apomictic plants ranging from 1:1 to 7:1 between $P$. notatum families of intraspecific crosses. These authors concluded that the segregation for apomixis depends on the genetic structure of sexual and apomictic parents.

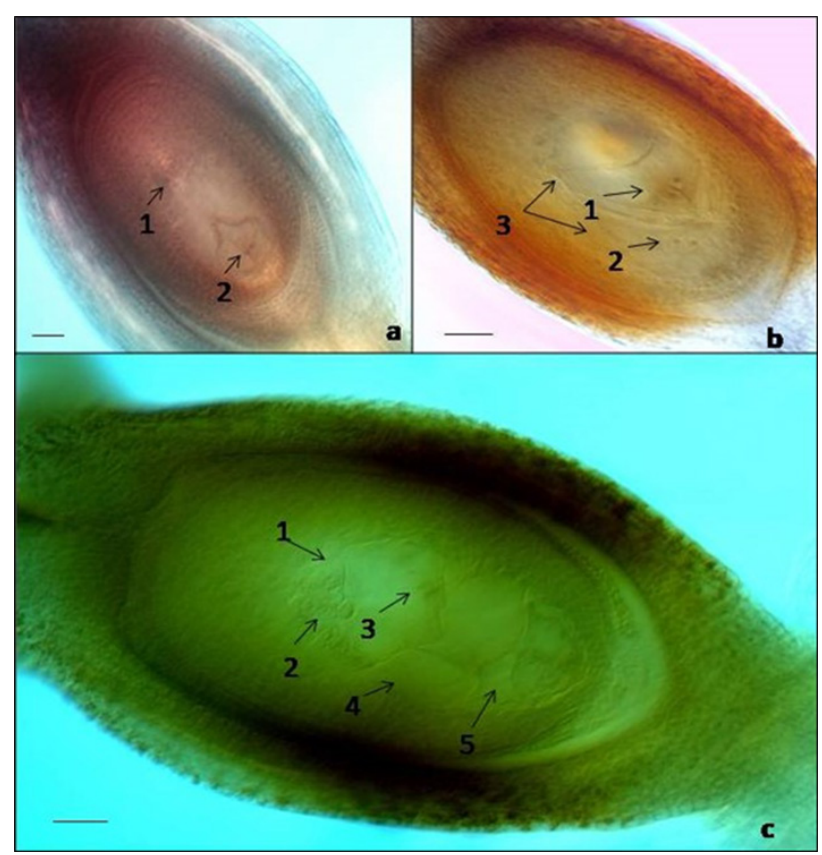

Figure 1. Morphology of embryo sacs. a) Sexual ovary of the KE1 plant with antipodes (1) and polar nuclei (2). b) Apomictic ovary of plant KF16 with polar nuclei (1 and 2) and two multiple sacs (3). c) Mixed ovary of plant KF8: sexual sac (1) with antipodes (2) and polar nuclei (3) and two apomictic sacs (4 and 5). Scale: $10 \mu \mathrm{m}$. 
The plant KF8 had 31 exclusively apomictic ovaries and 10 embryo sacs with a sexual as well as an apomictic sac (Figure 1c). Plants with both reproduction modes represented (co-exist in same ovule or in different ovules of the same plant) are considered as facultative apomictis (Kaushal et al. 2019, Yadav et al. 2019).

In a study with P. malacophyllum, Hojsgaard et al. (2013) described the competition between sexual and apomictic development of ovules and seeds with both embryo sacs in the same ovary, suggesting that this might be due to the genetic and epigenetic effects, causing instabilities in developmental programs. Epigenetic control of apomixis is an emerging theory being investigated on sexual plants in which mutations in epigenetic pathway genes resulted into apomixis-like phenotypes (Kumar 2017). The key factors reducing sexuality are the faster growth and parthenogenetic development in the aposporous pathway.

\section{Meiotic chromosome pairing analysis}

Based on counting of chromosome associations in diakinesis in pollen mother cells, all assessed apomictic hybrids confirmed polyploid.

Meiotic chromosome pairing was predominantly bivalent, but quadrivalent chromosome associations were also observed (Table 2; Figure 2). In bivalent associations, the chromosome matching of the evaluated tetraploid hybrids tended to be regular, although Quarin et al. (2001) claimed that quadrivalent associations predominate in apomictic tetraploids. In an evaluation of the meiotic behavior of plants 'WKS63' and 'WKS92' used as female parents in this experiment, Krycki et al. (2016) observed the predominance of bivalent associations in diakinesis and metaphase I, while uni, tri and quadrivalent associations also occurred, although sporadically.

In the study of Dahmer et al. (2008) in 36 apomictic $P$. notatum accessions collected in the state of Rio Grande do Sul, meiotic configurations at diakinesis and metaphase I varied from plants with only bivalents up to plants with high frequency of quadrivalents. The authors stated that all the examined accessions were potentially male-fertile and could be used as male genitors in crosses into the breeding program.

Table 2. Meiotic configurations of the diakinesis phase (prophase I) of apomictic $F_{1}$ hybrids

\begin{tabular}{|c|c|c|c|c|c|c|}
\hline \multirow{2}{*}{ Genotype } & \multirow{2}{*}{ Chromosome number } & \multirow{2}{*}{ Number of analyzed cells } & \multicolumn{4}{|c|}{ Mean of observed associations (range ${ }^{a}$ ) } \\
\hline & & & $\mathbf{l}^{\mathbf{b}}$ & $\mathrm{II}^{\mathrm{b}}$ & $\mathrm{III}^{\mathrm{b}}$ & $\mathrm{IV}^{\mathrm{b}}$ \\
\hline \multirow[t]{2}{*}{ KD1 } & 40 & 50 & 0 & 2.92 & 0 & 0.84 \\
\hline & & & 0 & $(0-20)$ & 0 & $(0-11)$ \\
\hline \multirow[t]{2}{*}{ KD2 } & 40 & 22 & 0 & 7.05 & 0 & 1.73 \\
\hline & & & 0 & $(0-20)$ & 0 & $(0-10)$ \\
\hline KD5 & 40 & 33 & 0 & 3.15 & 0 & 0.45 \\
\hline KD7 & & & 0 & $(0-20)$ & 0 & $(0-10)$ \\
\hline \multirow[t]{2}{*}{ KF3 } & 40 & 72 & 0 & 2.85 & 0 & 0.22 \\
\hline & & & 0 & $(10-20)$ & 0 & $(0-3)$ \\
\hline \multirow[t]{2}{*}{ KF6 } & 40 & 67 & 0 & 2.27 & 0 & 0.3 \\
\hline & & & 0 & $(9-20)$ & 0 & $(0-5)$ \\
\hline KF10 & & & 0 & $(10-20)$ & 0 & $(0-5)$ \\
\hline \multirow[t]{2}{*}{ KF16 } & 40 & 35 & 0 & 2.13 & 0 & 0.19 \\
\hline & & & 0 & $(14-20)$ & 0 & $(0-3)$ \\
\hline \multirow[t]{2}{*}{ KN3 } & 40 & 26 & 0 & 2.08 & 0 & 0.12 \\
\hline & & & 0 & $(16-20)$ & 0 & $(0-2)$ \\
\hline \multirow[t]{2}{*}{ KN5 } & 40 & 44 & 0 & 2.89 & 0 & 0.34 \\
\hline & & & 0 & $(10-20)$ & 0 & $(0-5)$ \\
\hline
\end{tabular}

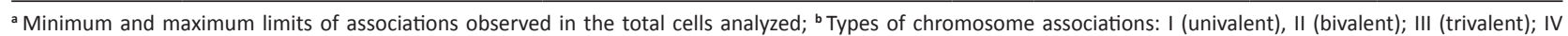
(quadrivalent). 
Other studies with tetraploid forage grass species $(2 n=$ $4 \mathrm{x}=40$ ) showed that some kind of abnormality can generally be observed in meiotic chromosome pairing of polyploid genotypes, mainly multivalent associations in diakinesis: Quarin (1994), Pagliarini et al. (2001), Araújo et al. (2005), Risso-Pascotto et al. (2005), Caetano et al. (2006), Reis et al. (2008), Simioni and Valle (2011).

According to Sybenga (1992), some abnormalities are possible and inherent to polyploid plants, generating pollen with an unbalanced chromosome number, a phenomenon that can affect the male fertility of these plants. This episode can induce the formation of cells that expose chromosome lagging, bridges, precocious ascension, and several other rare abnormalities.

\section{Pollen viability analysis}

The pollen viability of all 24 analyzed genotypes was high $(82.15 \%$ - 99.67\%), both for sexual and facultative apomictic plants (Table 3). Twenty-one hybrid genotypes had over $90 \%$ viable pollens, i.e. $72 \%$ of the total. These results demonstrate that the meiotic changes observed in pollen mother cells (data not shown) did not affect pollen viability. According with Pagliarini and Pozzobon (2004), apomictic $P$. notatum is pseudogamic, the pollen fertilizes only the endosperm, thus requiring a certain pollen viability.

In a study with Urochloa decumbens, Mendes-Bonato et al. (2002) estimated a mean pollen sterility of $52.73 \%$, based on the high rates of meiotic abnormalities in accessions of the species analyzed. However, despite the high sterility rate, seed production was not affected, leading to the conclusion that these plants were apomictic. The percentage of viable grains $(61.36 \%-64.86 \%)$ of freshly induced polyploidy Urochloa decumbens plants, was considered satisfactory by Simioni and Valle (2011), who stated that these plants could be used as parents in polycross blocks in the species breeding program. Tetraploid hybrids derived from crosses between $U$. ruziziensis and $U$. brizantha had mean pollen viability indices of $52.76 \%$ (Risso-Pascotto et al. 2005).

The pollen viability of the parents of $F_{1}$ hybrids was described as high by Krycki et al. (2016). The genotypes subjected to chromosome duplication, 'WKS63' and 'WKS92' had 88.7 and 95.7 of fertile pollen, respectively. The viability of the other parents also exceeded $85 \%$, except for genotype 'D25', with a fertility of $74.7 \%$. On the other hand, in the study of Dahmer et al. (2008), the pollen viability of $P$. notatum accessions ranged from 81 to $91.5 \%$; in $F_{1}$ hybrids, Podio et al. (2012) found from 66.1 to $84.7 \%$. and in P. lepton, Reis et al. (2008) found fertile pollens at rates of $88.99-95.06 \%$.

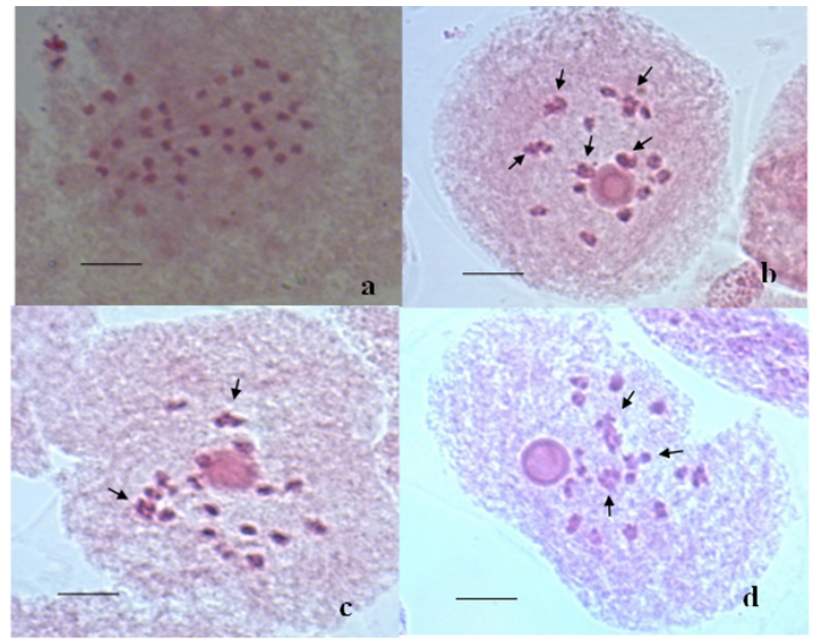

Figure 2. Chromosome associations in meiotic cells (meiosis I): a) plant KF16 (anaphase I with 40 chromosomes); b) plant KF6 (diakinesis with 10 bivalents and 5 quadrivalent associations); c) plant KF3 (diakinesis with 16 bivalents and 2 quadrivalent associations); d) plant KN5 (diakinesis with 14 bivalents and 3 quadrivalent associations). The arrows indicate the quadrivalent associations. Scale: $10 \mu \mathrm{m}$.

Table 3. Pollen viability of $F_{1}$ genotypes, apomictic and sexual progenies

\begin{tabular}{lc}
\hline Genotype & $\begin{array}{c}\text { Pollen viability } \\
\text { (\% stained pollen) }\end{array}$ \\
\hline KC1* & 91.04 \\
KD1** & 99.67 \\
KD2** & 95.29 \\
KD5** & 96.69 \\
KD6* & 96.25 \\
KD7** & 86.95 \\
KD9* & 93.79 \\
KE1* & 89.40 \\
KF1* & 86.14 \\
KF2* & 91.14 \\
KF3** & 93.81 \\
KF4* & 91.01 \\
KF6** & 89.43 \\
KF7* & 91.78 \\
KF8** & 94.28 \\
KF9* & 82.15 \\
KF10** & 86.78 \\
KF15* & 89.76 \\
KF16** & 98.63 \\
KF17* & 98.66 \\
KN2* & 94.55 \\
KN3** & 96.21 \\
KN4* & 98.64 \\
KN5** & 92.72 \\
\hline Sex* *** \\
\hline
\end{tabular}

* Sexual; ** Facultative apomictic. 
Comparing the percentages pollen viability data of experiments with species, accessions and hybrids of the genera Urochloa and Paspalum, viability of the latter was higher, although in all studies with Urochloa, the indices found in the evaluation were considered sufficient to validate them as parents for hybridization programs.

Analysis of the $F_{1}$ progenies in this study showed low presence of abnormalities in the meiotic chromosome pairing and high pollen viability. For the future crosses, the apomictic hybrids can be the male parents and the sexual plants can be used as female parents.

Besides that, the hybrid progenies were evaluated in field trials to verify the yield potential (data not show). Combined with the results of this study, genotypes with reproductive stability and satisfactory forage yield under field conditions will be included in new breeding cycles in our breeding program and, after testing in other evaluation phases, they may become cultivars candidates, with possibility of registration and protection.

\section{ACKNOWLEDGEMENTS}

The authors wish to thank the CAPES (Brazilian Federal Agency for Support and Evaluation of Graduate Education), CNPq (Brazilian Council for Scientific and Technological Development (CNPq), Universal call MCTI/CNPQ no. 14/2013, proc. 472665/2013-8) and Sulpasto (Associação Sul-brasileira Para o Fomento à Pesquisa de Forrageiras) for financial support and grants.

\section{REFERENCES}

Acuña CA, Blount AR, Quesenberry KH, Hanna WW and Kenworthy KE (2007) Reproductive characterization of bahiagrass germplasm. Crop Science 47: 1711-1717.

Acuña CA, Blount AR, Quesenberry KH, Kenworthy KE and Hanna WW (2011) Tetraploid bahiagrass hybrids: breeding technique, genetic variability and proportion of heterotic hybrids. Euphytica 179: 227-236.

Araújo ACG, Nóbrega JM, Pozzobon, MT and Carneiro VTC (2005) of sexuality in induced tetraploids of Brachiaria brizantha (Poaceae). Euphytica 144: 39-50.

Barbosa MR, Motta EAM, Machado JM, Krycki KC, Conterato IF, Weiler RL, Dall'Agnol M and Simioni C (2019) Herbage accumulation of bahiagrass hybrids in two different environments in southern Brazil. Pesquisa Agropecuária Gaúcha 25: 58-69.

Burton GW (1982) Improved recurrent restricted phenotypic selection increases bahiagrass forage yields. Crop Science 22: 1058-1061.

Caetano CM, Bonfá BRCN and Canto MW (2006) Autotetraploidia e número cromossômico em uma cultivar de Panicum maximum Jacq (Gramineae/Poaceae). Acta Agronomica 55: 62-66.

Dahmer N, Schifino-Wittmann MT, Dall'Agnol M and Castro B (2008) Cytogenetic data for Paspalum notatum Flügge accessions. Scientia Agricola 65: 381-388.

Fachinetto JM, Dall'Agnol M, Schifino-Wittmann MT, Simioni C and Ávila MR (2018) New wild diploids in Paspalum notatum Flügge (Poaceae): potential accessions for use in breeding. Crop Breeding and Applied Biotechnology 18: 432-436.

Forbes I and Burton GW (1961) Induction of tetraploid and rapid field method of detecting induced tetraploidy in Pensacola bahiagrass. Crop Science 1: 383-384.
Guerra D, Schifino-Wittmann MT, Schwarz SF, Souza PVD and Campos SS (2013) Reproductive characteristics of citrus rootstocks grown under greenhouse and field environments. Crop Breeding and Applied Biotechnology 13: 186-193.

Hojsgaard DH, Burson BL, Quarin CL and Martínez EJ (2016) Unravelling the ambiguous reproductive biology of Paspalum malacophyllum: a decade old story clarified. Genetic Resource and Crop Evolution 63: 1063-1071.

Hojsgaard DH, Martínez EJ and Quarin CL (2013) Competition between meiotic and apomictic pathways during ovule and seed development results in clonality. New physiologist 197: 336-347.

Kaushal P, Dwivedi KK, Radhakrishna A, Srivastava MK, Kumar V, Roy AC and Malaviya DR (2019) Partitioning apomixis components to understand and utilize gametophytic apomixis. Frontiers in Plant Science 10: 1-17.

Krycki KC, Simioni C and Dall'Agnol M (2016) Cytoembriyological evaluation, meiotic behavior and pollen viability of Paspalum notatum polyploidized plants. Crop Breeding and Applied Biotechnology 16: 282-288.

Kumar S (2017) Epigenetic control of apomixis: A new perspective of an old enigma. Advances in Plants \& Agriculture Research 7: 00243.

Kumar S, Saxena S and Gupta MC (2017) Marker-assisted screening of breeding populations of an apomictic grass Cenchrus ciliaris L. segregating for the mode of reproduction. Crop Breeding and Applied Biotechnology 17: 10-17, 2017.

Kumar S, Chandra A, Gupta MG and Shukla GP (2010a) Molecular and embryological analyses of rare sexual plant in Buffelgrass (Cenchrus ciliaris L.). Range Management and Agroforesty 31: 36-40.

Kumar S, Chandra A, Gupta MG and Shukla GP (2010b) SCAR marker linked to sexuality in Cenchrus ciliaris L. Range Management and Agroforestry 31: 149-150. 
Reproductive analyses of intraspecific Paspalum notatum Flügge hybrids

Martínez EJ, Acuña C A, Hojsgaard DH, Tcach M and Quarin CL (2007) Segregation for sexual seed production in Paspalum as directed by male gametes of apomictic triploid plants. Annals of Botany 100: 1239-1247.

Martínez EJ, Urbani MH, Quarin CL and Ortiz JP (2001) Inheritance of apospory in bahiagrass, Paspalum notatum. Hereditas 135: 19-25.

Mendes-Bonato AB, Valle CB, Pagliarini MS and Penteado MIO (2002) Caracterização citogenética de acessos de Brachiaria brizantha (Gramineae). Boletim de Pesquisa e Desenvolvimento 15. EMBRAPA, Campo Grande, 31p.

Miles JW (2007) Apomixis for cultivar development in tropical forage grasses. Crop Science 47: 238-249.

Nabinger C and Dall'Agnol M (2008) Principais gramíneas nativas do RS: características gerais, distribuição e potencial forrageiro. In Dall'Agnol $\mathrm{M}$, Nabinger $\mathrm{C}$ and Santos RJ (eds) Anais do $3^{\circ}$ simpósio de forrageiras e produção animal. UFRGS, Porto Alegre, p.7-54.

Ortiz JPA, Quarin CL, Pessino SC, Acuña C, Martínez EJ, Espinoza F, Hojsgaard DH, Sartor ME, Cáceres ME and Pupilli F (2013) Harnessing apomictic reproduction in grasses: what we have learned from Paspalum. Annals of Botany 112: 767-787.

Pagliarini MS and Pozzobon MT (2004) Meiose vegetal: um enfoque para a caracterização de germoplasma. In Peñaloza APS (ed) Anais do II curso de citogenética aplicada a recursos genéticos vegetais. EMBRAPA, Brasília, p. 24-41.

Pagliarini MS, Carraro LR, Freitas PM, Adamowski EV, Batista LAR and Valls JFM (2001) Cytogenetic characterization of Brazilian Paspalum acessions. Hereditas 35: 27-34.

Podio M, Siena LA, Hojsgaard D, Stein J, Quarin CL and Ortiz JPA (2012) Evaluation of meiotic abnormalities and pollen viability in aposporous and sexual tetraploid Paspalum notatum (Poaceae). Plant Systematics and Evolution 298: 1625-1633.

Quarin CL (1994) A Tetraploid cytotype of Paspalum durifolium: cytology, reproductive behavior and this relationship to diploid $P$. intermedium. Hereditas 121: 115-118.

Quarin CL, Espinoza F, Martínez EJ, Pessino SC and Bovo OA (2001) A rise of ploidy level induces the expression of apomixis in Paspalum notatum. Sexual Plant Reprodution 13: 243-249.

Reis CAO, Schifino-Wittmann MT and Dall'Agnol M (2008) Chromosome numbers, meiotic behavior and pollen fertility in a collection of Paspalum nicorae Parodi accessions. Crop Breeding and Applied Biotechnology 8: 212-218.
Risso-Pascotto C, Pagliarini MS and Valle CB (2005) Multiple spindle sand cellularization during microsporogenesis in an artificial induced tetraploid accession of Brachiaria ruziziensis (Gramineae). Plant Cell Reports 23: 522-527.

Simioni C and Valle CB (2011) Meiotic analysis in induced tetraploids of Brachiaria decumbens Stapf. Crop Breeding and Applied Biotechnology 11: 43-49.

Simioni C and Valle CB (2009) Chromosome duplication in Brachiaria (A. Rich.) Stapf allows intraspecific crosses. Crop Breeding and Applied Biotechnology 9: 328-334.

Singh RJ (1993) Plant cytogenetics. CRC Press, Boca Ratton, 391p.

Stein J, Quarin CL, Martínez EJ, Pessino SC and Ortiz JPA (2004) Tetraploid races of Paspalum notatum show polysomic inheritance and preferential chromosome pairing around the apospory-controlling locus. Theoretical and Applied Genetics 109: 186-191.

Sybenga J (1992) Cytogenetics and plant breeding. Springer Verlag, Berlin, 469p.

Tedesco M, Emer AA, Winhelmann MC, Avrella ED, Krycki KC, Simioni C and Schafer G (2019) Cytogenetic characterization of Angelonia integerrima Sprengel, a native species with ornamental potential. Crop Breeding and Applied Biotechnology 19: 118-125.

Weiler LR, Dall'Agnol M, Simioni C, Krycki KC, Pereira EA, Machado JM and Motta EAM (2018) Intraespecific tetraploid hybrids of Paspalum notatum: agronomic evaluation of segregation progeny. Scientia Agricola 75: 36-42.

Weiler RL, Dall'Agnol M, Simioni C, Krycki KC, Dahmer N and Guerra D (2017) Determination of the mode of reproduction of bahiagrass hybrids using cytoembryological analysis and molecular markers. Revista Brasileira de Zootecnia 46: 185-191.

Weiler RL, Krycki KC, Guerra D, Simioni C and Dall'Agnol M (2015) Chromosome doubling in Paspalum notatum var. saure (cultivar Pensacola). Crop Breeding and Applied Biotechnology 15: 106-111.

Yadav CB, Dwivedi A, Kumar S and Bhat V (2019) AFLP-based genetic diversity analysis distinguishes apomictically and sexually reproducing Cenchrus species. Brazilian Journal of Botany 42: 361-371.

Young BA, Sherwood RT and Bashaw EC (1979) Cleared-pistil and thick sectioning techniques for detecting aposporus apomixis in grasses. Canadian Journal of Botany 57: 1668-1672.

Zilli AL, Brugnoli EA, Marcón F, Billa MB, Rios EF, Martínez EJ and Acuña CA (2015) Heterosis and expressivity of apospory in tetraploid bahiagrass hybrids. Crop Science 55: 1189-1201.

(cc) EY This is an Open Access article distributed under the terms of the Creative Commons Attribution License, which permits unrestricted use, distribution, and reproduction in any medium, provided the original work is properly cited. 